\title{
Isparta elma bahçelerinden toplanan Panonychus ulmi Koch (Acari: Tetranychidae) popülasyonlarının abamectin, chlorpyrifos ethyl ve bifenthrin'e karşı direnç düzeylerinin belirlenmesi
}

\author{
Abamectin, chlorpyrifos ethyl and bifenthrin resistance in Panonychus ulmi Koch. \\ (Acari:Tetranychidae) populations collected from apple orchards in Isparta
}

\author{
Naciye Sena ÇAĞATAY ${ }^{1}$ \\ Sibel YORULMAZ SALMAN ${ }^{1}$ \\ Yasemin YAMAN ${ }^{1}$ \\ Recep $A Y^{1^{*}}$
}

\begin{abstract}
Summary
The spider mites are the second pest group which is tried to be managed in apple orchards following codling moth. The chemical control is generally preferred against spider mites. However, chemical control may lead to resistance in pests in the long time. The resistance development may lead to increase the pesticide usage. Because the dose and spray frequency of pesticides for the management of resistant pest population has been increased mostly. This study was conducted to determine the resistance against abamectin, chlorpyrifos ethyl and bifenthrin in Panonychus ulmi Koch (Acari: Tetranychidae) populations from apple orchards in Isparta. The $\mathrm{LC}_{50}$ values were determined in mentioned populations. The resistance ratios were determined dividing the $\mathrm{LC}_{50}$ values of susceptible population to the $\mathrm{LC}_{50}$ values of orchard populations. According to $\mathrm{LC}_{50}$ value, the resistance ratios against abamectin, chlorpyrifos ethyl and bifenthrin of $P$. ulmi orchards populations are $0.75-2.25,0.57-1.76$ and $1.19-3.78$ fold, respectively.
\end{abstract}

Key words: $P$. ulmi, apple, bifenthrin, abamectin, chlorpyrifos ethyl

\section{Özet}

Elma bahçelerinde elma içkurdundan sonra en fazla savaşım yapılan zararlılar arasında kırmızı̈rümcekler yer almaktadır. Kırmızıörümceklere karşı genellikle kimyasal mücadele tercih edilmektedir. Fakat, kimyasal mücadele zaman içerisinde zararılıarda direnç sorununa yol açabilmektedir. Zararlılarda direnç gelişimi, dirençli zararılıarı kontrol altına almak için daha yüksek dozlarda ve daha sık uygulamalar yüzünden daha fazla kimyasal kullanımına neden olmaktadır. Bu çalışma, Isparta ilindeki elma bahçelerinden toplanan Panonychus ulmi Koch (Acari: Tetranychidae) popülasyonlarında abamectin, chlorpyrifos ethyl ve bifenthrin'e karşı direnç düzeylerinin belirlenmesi amacıyla yapılmıştır. Toplanan popülasyonlarda bu akarisitlere karşı $L_{50}$ değerleri belirlenmiştir. Direnç oranları, bahçe popülasyonları için belirlenen $\mathrm{LC}_{50}$ değerlerinin hassas popülasyonun $\mathrm{LC}_{50}$ değerine bölünmesiyle elde edilmiştir. LC $_{50}$ değerleri dikkate alındığında, bahçelerden alınan $P$. ulmi popülasyonlarının abamectin, chlorpyrifos ethyl ve bifentrin'e karsı göstermiş olduğu direnç oranları sırasıyla 0.75-2.25, 0.57-1.76 ve 1.19- 3.78 kat arasında değişmiştir.

Anahtar sözcükler: P. ulmi, elma, bifenthrin, abamectin, chlorpyrifos ethyl.

\footnotetext{
${ }^{1}$ Süleyman Demirel Üniversitesi, Ziraat Fakültesi, Bitki Koruma Bölümü, Isparta

* Sorumlu yazar (Corresponding author) e-mail: recepay@sdu.edu.tr

Alınış (Received): 22.10.2014 Kabul ediliş (Accepted): 05.12.2014
} 


\section{Giriş}

Elma (Malus communis L.) Türkiye'de üreticisine yüksek gelir sağlayan meyve türlerinden birisidir. Türkiye, elma üretimi açısından, Çin ve ABD'den sonra 2.600 .000 ton ile Dünyada 3 . sırada yer almaktadır (Anonymous, 2012). Türkiye istatistik Kurumu'nun 2013 verilerine göre, Türkiye'de üretilen 3.128.450 ton elmanın yaklaşık 634.862 tonu Isparta ilinde üretilmiştir (Anonymous, 2013).

Elma yetiştiriciliğini sınırlayan pek çok hastalık ve zararlı vardır. Zararılardan özellikle elma içkurdu ve akarlar önemli ekonomik kayıplara neden olmaktadır. Akarlardan Avrupa kırmızı̈rümceği, Panonychus ulmi Koch, 1940'ların başında ekonomik açıdan önemli bir zararlı değilken (Chant, 1966), günümüzde kimyasal savaşımın yaygınlaşması ve bunun sonucu doğal düşmanların olumsuz etkilenmesi nedeniyle elma bahçelerinin önemli zararılıarından biri haline gelmiştir. P. ulmi, yaprak döken çalılar ve özellikle Rosacae familyasına ait elma, armut, erik, şeftali gibi ekonomik değeri yüksek olan meyve ağaçlarında zararlı olmaktadır (Croft, 1975). Kırmızıörümcekler, yoğunluklarının düşük olduğu zaman, genellikle yaprak üzerindeki damar boyunca bulunurlar ve bitki öz suyu ile beslenirler (Blair \& Groves, 1952). P. ulmi beslenmesine maruz kalan yaprakların fotosentez aktivitesi azalır (Mobley \& Marini, 1990). Bu zarar mevcut yıl ve bir sonraki yılı etkileyebilir. Mevcut yıl zarar şiddetine bağlı olarak yaprağın nitrojen seviyesini düşürerek, yaprakların erken dökülmesine neden olabilirler. Sürgün gelişimini zayıflatırlar ve en önemlisi ürün miktarını düşürürler. Isparta'da üreticiler zararlı ve hastalıklara karşı daha çok kimyasal savaşımı tercih etmektedirler (Boyraz et al., 2005).

Zararlı ile mücadelede, kimyasal mücadele yöntemlerinin yaygın olarak kullanılmasının nedeni, kısa sürede etki göstermesi ve uygulamasının kolay olmasıdır. Isparta ilindeki elma bahçelerinde bir üretim sezonunda ortalama 12-43 ilaçlama yapıldığı bildirilmiştir (Demircan et al., 2005). Isparta ilinde 2013 yılında Gıda Tarım ve Hayvancılık Bakanlığı Isparta İı Müdürlüğü'ne göre 1.065.259 ton ilaç satılmış ve bu ilaçların 141.921 tonunu insektisitler ve 55.997 tonunu akarisitler oluşturmaktadır (Anonymous, 2013a). Tarımsal mücadele açısından düşünüldüğünde, zararlıların yoğun kullanılan tarım ilaçlarına karşı direnç kazanması olası bir durumdur. Pestisitlere karşı oluşan direnç pek çok zararıda görülen önemli bir problemdir. Aynı etki mekanizmasına sahip ilaç veya ilaçların tekrarlı bir şekilde uygulanması zararlı popülasyon için kullanılan kimyasallara karşı direnç oluşma riskini artırmaktadır. Direnç, normal bir popülasyondaki bireylerin çoğunu öldürdüğü tespit edilen bir kimyasal maddenin belirli bir dozuna karşı, aynı popülasyondaki bazı bireylerin tolerans kazanma yeteneğidir (Hamingway, 1998).

Bu çalışmada Isparta ili ve ilçelerinde, elma bahçelerinde zararlı olan $P$. ulmi popülasyonlarının abamectin, chlorpyrifos ethyl ve bifenthrin'e karşı direnç düzeylerinin belirlenmesi amaçlanmıştır.

\section{Materyal ve Yöntem}

\section{Panonychus ulmi popülasyonlarının toplanması ve kültüre alınması}

Isparta ili ve ilçelerinde bulunan elma bahçelerinden tesadüfen seçilen bahçelerinden toplanan akarla bulaşık yapraklar naylon poşetlere konarak etiketlenmiş ve buz kapları ile SDÜ Ziraat Fakültesi, Bitki Koruma Bölümü Laboratuvarı'na getirilmiştir (Çizelge 1). Getirilen kırmızıörümcek popülasyonları temiz elma ve erik fidanlarında iklim odalarında üretime alınmıştır. Denemelerde, 1990 yılından bu yana ilaçsız ortamda yetiştirilen P. ulmi'nin hassas popülasyonu (GSS) ise Bayer Crop Science firmasından 2011 yılında sağlanmıştır. 
Çizelge. 1 Panonychus ulmi popülasyonlarının toplanma yerleri ve tarihleri

\begin{tabular}{ll}
\hline Popülasyon Adı & Toplanma Tarihleri \\
\hline Ağılköy & 15.06 .2013 \\
Yalvaç & 15.06 .2013 \\
Bağıllı & 15.06 .2013 \\
Gönen & 22.06 .2013 \\
Gelendost & 22.06 .2013 \\
Büyükkabaca & 22.06 .2013 \\
Büyük Gökçeli & 22.06 .2013 \\
\hline
\end{tabular}

\section{Panonychus ulmi popülasyonlarının kitle üretimi}

Laboratuvara getirilen $P$. ulmi ile bulaşık yapraklar binoküler altında kontrol edildikten sonra akarlı yapraklar, içi su dolu küvetler içerisindeki elma (Malus domestica Borckhausen) ve erik (Prunus domestica Angeleno) fidanlarına yerleştirilerek kabine alınmıştır. Kabin $26 \pm 1^{\circ} \mathrm{C}$ sıcaklık, $\% 60 \pm 5$ nem ve 16:8 fotoperiyot koşullarına ayarlanmıştır. $P$. ulmi'nin kitle üretimi ve bioassay denemelerinde elma ve erik ağaçları kullanılmıştır. Elma ve erik ağaçlarının üretimleri de $23 \pm 1^{\circ} \mathrm{C}$ sıcaklıkta ve $16: 8 \mathrm{~A}: \mathrm{K}$ fotoperiyot koşullarının sağlandığı iklim odasında yapılmıştır.

\section{İlaçlar}

Çalışmada kullanılan ilaçlar kırmızıörümceklere ve diğer zararılıara karşı yaygın kullanılan ilaçlar arasından seçilmiştir. Bunlar, chlorpyrifos ethyl, abamectin ve bifenthrin etkili maddeli ilaçlardır. Çalışmada chlorpyrifos ethyl'in dursban 4 EC (480g/l) formülasyonu, bifentrin'in omstar 100 EC ( $100 \mathrm{~g} / \mathrm{l})$ ve abamectin'in agrimec EC (18 g /l) dir.

\section{Metod}

Bu çalışmada, P. ulmi'nin yaygın kullanılan ilaçlara karşı duyarlılığı biyoassay yöntemlerle incelenmiştir. Biyoassay denemelerinde kulanılacak akarisitler ergin dönemine etkili olduğu için ilaçlar ergin döneme uygulanmıştır. Ön çalışmalarda popülasyonlarda \% 10 ve \% 95-99 ölüm veren dozlar belirlenmiş ve daha sonra ara dozlar ayarlanmıştır. Dozların seyreltilmesinde saf su kullanılmıştır.

İlaçlar petri kabı içinde ıslak pamuk üzerindeki erik yapraklarında bulunan erginlere uygulanmıştır. Bu amaçla, çapı $9 \mathrm{~cm}$ olan petrilere pamuklar yerleştirilmiş ve üzerine temiz erik yaprakları alt yüzeyi pamuğa gelecek şekilde konulmuştur. Erik yapraklarının üzerine 25-30 P. ulmi ergin dişi bireyleri yumuşak uçlu fırça yardımıyla aktarıımıştır. Petrilerin hava almasını sağlamak için kapaklarında iğne ucu ısıtılarak 3 adet delik açılmıştır. Petrilere $2 \mathrm{ml}$ olacak şekilde ilaçlama kulesi (Auto loaded, Burkard Scientific- England) ile 1 bar basınçla homojen olarak ilaç uygulanmıştır. İlaçlar uygulandıktan sonra bu petriler $26 \pm 1 \mathrm{C}^{\circ}$ sıcaklık ve \% 60 \pm 5 nem oranına sahip, florasan lambalar ile 16 saat ışık ve 8 saat karanlık koşullarındaki iklim odalarına bırakılmıştır. Ölü-canlı sayımı 24 saat sonra binoküler altında yapılmıştır. Her deneme için 1 kontrol ve 7 doz ilaç uygulanmıştır. Her doz 3 tekerrürlü olarak çalışıımıştır. Popülasyonların ölü-canlı sayımları 1. günde yapılmıştır. Sayım sonuçlarından elde edilen verilerlerden yararlanarak POLO bilgisayar paket programında (LeOra Software, Berkeley, CA 1994) probit analiz yöntemiyle popülasyonların LC $_{50}$ değerleri, eğimleri ve \% 95 güven aralıkları elde edilmiştir. Direnç katsayıları $(R R)$, bahçe popülasyonlarının $L_{50}$ değerlerinin hassas popülasyonun $L_{50}$ değerlerine bölünmesiyle bulunmuştur.

$$
\mathrm{LC}_{50} \text { Direnç Katsayısı (RR) }=\frac{\text { Bahçe popülasyonun } \mathrm{LC}_{50} \text { değeri }}{\text { Hassas popülasyonunun } \mathrm{LC}_{50} \text { değeri }}
$$




\section{Araştırma Sonuçları ve Tartışma}

Isparta ili ve çevresindeki ilçelerde yoğun elma üretimi yapılan yerlerden toplanan $P$. ulmi popülasyonları ile hassas popülasyonun abamectin, chlorpyrifos ethyl, bifenthrin'e karsı duyarlılık düzeyleri belirlenmiştir ve Çizelge 2, 3 ve 4'te verilmiştir.

Direnç oranları (katı), elma bahçelerinden toplanan $P$. ulmi popülasyonlarının $L_{5} C_{50}$ değerlerinin hassas popülasyonun $\mathrm{LC}_{50}$ değerine bölünmesiyle elde edilmiştir. Elma bahçelerinden toplanan $P$. ulmi popülasyonlarının abamectin'e karşı LC $_{50}$ değerine göre göstermiş oldukları direnç oranları, $0.75-2.25$ kat arasında değişmiştir. Abamectin'e karsı en yüksek direnç oranı Ağılköy popülasyonda, en düşük direnç oranı 0.75 kat ile Gönen ve Büyükkabaca popülasyonlarında belirlenmiştir (Çizelge 2). Farklı bir tür olmakla birlikte Ay et al. (2005) Isparta' da örtüaltı sebzelerinden toplamış oldukları T. urticae popülasyonlarında abamectin'e karşı 1.0 - 2.9 kat duyarlılık kaybı bulmuşlardır. Ek olarak, Ay (2006), Antalya'da farklı sebze üretim seralarından toplanan T. urticae popülasyonlarında abamectin'e karşı, 1.07 - 1.82 kat duyarııık kaybı olduğunu belirtmiştir.

Çizelge 2. Panoychus ulmi'nin 2013 yılı popülasyonlarında abamectin için elde edilen LC $_{50}$ değerleri ve direnç oranları

\begin{tabular}{|c|c|c|c|c|}
\hline Popülasyon & $\mathrm{n}^{*}$ & Eğimse & $\begin{array}{r}{ }^{*} \mathrm{LC}_{50} \mathrm{mg} / \mathrm{L} \\
(\% 95 \text { Güven aralıkları) }\end{array}$ & Direnç oranı \\
\hline Hassas & 463 & $1.577 \pm 0.151$ & $\begin{array}{r}0.04 \\
0.03-0.05\end{array}$ & \\
\hline Ağılköy & 395 & $1.952 \pm 0.231$ & $\begin{array}{r}0.09 \\
0.07-0.12\end{array}$ & 2.25 \\
\hline Büyük Gökçeli & 422 & $1.879 \pm 0.201$ & $\begin{array}{r}0.07 \\
0.06-0.09\end{array}$ & 1.75 \\
\hline Gelendost & 398 & $2.166 \pm 0.263$ & $\begin{array}{r}0.10 \\
0.04-0.16\end{array}$ & 2.5 \\
\hline Gönen & 444 & $1.534 \pm 0.157$ & $\begin{array}{r}0.03 \\
0.02-0.04\end{array}$ & 0.75 \\
\hline Büyük Kabaca & 490 & $1.418 \pm 0.142$ & $\begin{array}{r}0.04 \\
0.03-0.05\end{array}$ & 1.0 \\
\hline Yalvaç & 486 & $1.233 \pm 0.131$ & $\begin{array}{r}0.03 \\
0.02-0.04\end{array}$ & 0.75 \\
\hline Bağıllı & 384 & $2.008 \pm 0.222$ & $\begin{array}{r}0.05 \\
0.04-0.07\end{array}$ & 1.25 \\
\hline
\end{tabular}

${ }^{*}$ n:denemede kullanılan birey sayı, ${ }^{* *}$ değerler aktif madde olarak verilmiştir

Hu et al. (2009) Çin'deki portakal bahçelerinden topladıkları Panonychus citri (McGregor) (Acari: Tetranychidae) popülasyonlarında abamectin'e karşı 1- 153 kat arasında direnç olduğunu rapor etmişlerdir. Nauen et al. (2001) topladıkları sekiz farklı P. ulmi popülasyonunun larva dönemlerinin abamectin'e karşı 1.8-2.2 kat direnç gösterdiğini belirlemişlerdir.

P. ulmi popülasyonlarının chlorpyrifos ethyl'e karşı göstermiş oldukları direnç oranları 0.57-1.76 kat arasında değişmiştir (Çizelge 3). Chlorpyrifos ethyl'e karşı en yüksek direnç oranı Yalvaç popülasyonunda, en düşük direnç oranı Büyükkabaca popülasyonunda belirlenmiştir. Ay et al. (2005), Antalya ve Isparta illeri sebze seralarından topladıkları $T$. urticae popülasyonlarının chlorpyrifos'a karşı 81774 kat direnç gösterdiğini belirtmişlerdir. Nauen et al. (2001), P. ulmi larvalarının Almanya, Avustralya, Japonya, Fransa, İtalya, Amerika (Kaliforniya ve Florida) ve Brezilya ırklarının, chlorpyrifos'a karşı 0.232.5 kat arsında direnç gösterdiğini rapor etmişlerdir. Sökeli et al. (2005), Isparta ili ve çevresindeki elma bahçelerinden toplanan $T$. urticae popülasyonlarının chlorpyrifos'a 2.341-40.206 kat direnç geliştirdiklerini bulmuşlardır. Ay \& Yorulmaz (2009) bifentrine $20 \mathrm{kez}$ selekte ettikleri T. urticae popülasyonunun chlorpyrifos ethyl'e karşı 4.72 kat çapraz direnç geliştirdiğini belirlemişlerdir. 
Çizelge 3. Panoychus ulmi'nin 2013 yılı popülasyonlarında chlorpyrifos ethyl için elde edilen LC $_{50}$ değerleri ve direnç oranlar

\begin{tabular}{|c|c|c|c|c|}
\hline Popülasyon & $\mathrm{n}^{*}$ & Eğim \pm se & $\begin{array}{r}{ }^{* *} \mathrm{LC}_{50} \mathrm{mg} / \mathrm{L} \\
(\% 95 \text { Güven aralıkları) }\end{array}$ & Direnç oranı \\
\hline \multirow[t]{2}{*}{ Hassas } & 439 & $2.501 \pm 0.279$ & 766.142 & \\
\hline & & & $376.699-1130.942$ & \\
\hline \multirow[t]{2}{*}{ Ağılköy } & 401 & $1.651 \pm 0.273$ & 923.529 & 1.20 \\
\hline & & & $452.668-1365.105$ & \\
\hline \multirow[t]{2}{*}{ BüyükGökçeli } & 395 & $3.542 \pm 0.491$ & 907.084 & 1.18 \\
\hline & & & 548.376- 1137.950 & \\
\hline \multirow[t]{2}{*}{ Gelendost } & 351 & $1.388 \pm 0.178$ & 1078.939 & 1.40 \\
\hline & & & $729.585-1359.628$ & \\
\hline \multirow[t]{2}{*}{ Büyük Kabaca } & 431 & $1.717 \pm 0.175$ & 438,504 & 0.57 \\
\hline & & & $190.252-713.961$ & \\
\hline \multirow[t]{2}{*}{ Yalvaç } & 471 & $3.650 \pm 0.644$ & 1355.764 & 1.76 \\
\hline & & & 763.641-1694.856 & \\
\hline \multirow[t]{2}{*}{ Bağıllı } & 368 & $1.845 \pm 0.237$ & 534.019 & 0.69 \\
\hline & & & $148.574-279.278$ & \\
\hline
\end{tabular}

*n: denemede kullanılan birey sayısı, $\quad{ }^{* *}$ değerler aktif madde olarak verilmiştir

P. ulmi popülasyonlarının bifenthrin'e karşı göstermiş oldukları direnç oranları 1.19-3.78 kat arasında değişmiştir (Çizelge 4). Bifentrin'e karsı en yüksek direnç oranı Büyükkabaca popülasyonunda, en düşük direnç oranı Yalvaç popülasyonunda belirlenmiştir. Akgünlü (2005), Adana, Isparta, Diyarbakır, Mardin ve Urfa'dan farklı kültür bitkileri üzerinden topladığı 11 farklı $T$. urticae popülasyonunda sentetik piretroitlerden bifenthrine karşı 1.396-7.957 kat aralıklarında direnç belirlemiştir. Ay \& Gürkan (2005), T. urticae'nin Adana, Antalya, İzmir, Manisa ve Urfa'dan topladıkları dokuz farklı popülasyonunda bifenthrine karşı $L_{50}$ değerine göre <1-669 kat direnç geliştirdiğini belirtmişlerdir. Ay \& Yorulmaz (2009), bifentrin ile 20 kez selekte ettikleri $T$. urticae popülasyonunda 21.84 kat direnç geliştiğini bulmuşlardır. Tsagkarakou et al. (2009), yoğun ilaç uygulanan bir gül serasından topladıkları ve iki dölde bir seleksiyona tabi tuttukları T. urticae'nin ATHRos-Bf ırkında bifenthrin'e karşı 2495 kat direnç belirlemişlerdir. Van Leeuwen \& Tirry (2007), T. urticae'nin seradan topladıkları popülasyonunda yüksek oranda bifenthrin direnci belirlemişlerdir.

Kırmızıörümceklerin pestisitlere karşı duyarlılık durumunun belirlenmesi için çok sayıda çalışma yapılmıştır. Ancak Türkiye'de elma bahçelerinde Avrupa kırmızıörümceklerinin duyarlıı̆ı konusunda yapıımış çalışma sayısı azdır. Bu çalışmada elde edilen sonuçlara göre, Isparta ilindeki elma bahçelerinden alınan Avrupa kırmızıörümceği popülasyonlarında söz konusu zararlıya karşı kullanılan abamectin ve bifenthrin için ve ayrıca elmada diğer birçok zararlıya karşı yaygın kullanılan chlorpyrifos ethyl için önemli bir duyarlılık kaybı belirlenmemiştir. Zararlılarla savaşımda kimyasal savaş sıklıkla tercih edilen bir yöntemdir. Etkili bir kimyasal savaşım için zararlılarda duyarlılık düzeyleri ve uygun direnç belirleme yöntemlerinin bilinmesinde yarar vardır. Direncin önlenmesi veya geciktirilmesi için, zararlıların duyarlılık düzeylerinin periyodik aralıklarla kontrol edilip belirlenmesi gereklidir. 
Isparta elma bahçelerinden toplanan Panonychus ulmi Koch (Acari: Tetranychidae) popülasyonlarının abamectin, chlorpyrifos ethyl ve bifenthrin'e karşı direnç düzeylerinin belirlenmesi

Çizelge 4. Panoychus ulmi'nin 2013 yılı popülasyonlarında bifenthrin için elde edilen LC $_{50}$ değerleri ve direnç oranları

\begin{tabular}{|c|c|c|c|c|}
\hline Popülasyon & $n^{*}$ & Eğim_se & $\begin{array}{r}{ }^{*}{ }^{*} \mathrm{C}_{50} \mathrm{mg} / \mathrm{L} \\
(\% 95 \text { Güven aralıkları) }\end{array}$ & $\begin{array}{r}\text { Direnç } \\
\text { oranı }\end{array}$ \\
\hline \multirow[t]{2}{*}{ Hassas } & 507 & $1.021 \pm 0.115$ & 59.468 & \\
\hline & & & $38.722-84.983$ & \\
\hline \multirow[t]{2}{*}{ Ağılköy } & 392 & $1.932 \pm 0.277$ & 142.613 & 2.39 \\
\hline & & & $104.258-180.705$ & \\
\hline \multirow[t]{2}{*}{ BüyükGökçeli } & 371 & $2.208 \pm 0.396$ & 96.785 & 1.63 \\
\hline & & & $35.988-144.995$ & \\
\hline \multirow[t]{2}{*}{ Gelendost } & 308 & $1.907 \pm 0.295$ & 118.244 & 1.99 \\
\hline & & & $59.876-171.153$ & \\
\hline \multirow[t]{2}{*}{ Gönen } & 370 & $1.987 \pm 0.208$ & 73.494 & 1.24 \\
\hline & & & $54.727-110.489$ & \\
\hline \multirow[t]{2}{*}{ Büyük Kabaca } & 462 & $1.732 \pm 0.219$ & 225.027 & 3.78 \\
\hline & & & $122.528-318.752$ & \\
\hline \multirow[t]{2}{*}{ Yalvaç } & 492 & $1.732 \pm 0.219$ & 70.961 & 1.19 \\
\hline & & & $21.225-123.811$ & \\
\hline \multirow[t]{2}{*}{ Bağıllı } & 308 & $2.308 \pm 0.343$ & 142.850 & 2.40 \\
\hline & & & $108.147-59.760$ & \\
\hline
\end{tabular}

*n: denemede kullanılan birey sayısı, ** değerler aktif madde olarak verilmiştir

\section{Teşekkürler}

Panonychus ulmi popülasyonlarının tür teşhisini yapan Prof. Dr. Sultan ÇOBANOĞLU (Ankara Üniversitesi)'na ve çalışmaya destek veren TÜBITTAK (Proje no: 1100631)'a teşekkür ederiz.

\section{Yararlanılan Kaynaklar}

Akgünlü, F. Z., 2005. Tetranychus urticae Koch (Acari: Tetranychidae)'nin Değişik Popülasyonlarının Sentetik Piretroitli İlaçlara Karşı Meydana Getirdiği Direncin İzlenmesi. Ankara Üniversitesi, Fen Bilimleri Enstitüsü, (Basılmamış) Yüksek Lisans Tezi, Ankara, $41 \mathrm{~s}$.

Anonymous, 2012. FAO, Statistical Database. (Web adresi: http://www.fao.org) (Erişim Tarihi: 26.09.2014).

Anonymous, 2013. T.C. Başbakanlık Türkiye İstatistik Kurumu Başkanlığı, Ankara. (Web adresi: http://www.tuik.gov.tr) (Erişim tarihi: 26.09.2014).

Anonymous, 2013a. Gıda, Tarım ve Hayvancılık Bakanlığı Isparta ilı Müdürlüğü.

Ay, R., 2005. Determination of susceptibility and resistance of some greenhouse populations of Tetranychus urticae Koch to chlorpyrifos (Dursban 4) by the petri dish-Potter tower method. Journal of Pest Science, 78: 139-143.

Ay, R., E. Sökeli \& I Karaca, 2005. Enzyme variation among some southwest Turkey populations of the two-spotted spider mite, Tetranychus urticae Koch. Journal of Pest Science, 78:175-178.

Ay, R., E. Sökeli I Karaca \& M.O. Gürkan, 2005. Response to some acaricides of two-spotted spider mite (Tetranychus urticae Koch) from protected vegetables in Isparta (Turkey). Turkish Journal of Agriculture and Forestry, 29: 165-171. 
Ay, R. \& M.O. Gürkan, 2005. Resistance to bifenthrin and resistance mechanisms of different strains of the twospotted spider mite (Tetranychus urticae) from Turkey. Phytoparasitica, 33(3): 237-244.

Ay, R., 2006. Antalya ili örtüaltı sebze üretim alanlarında zararlı olan Tetranychus urticae Koch popülasyonlarının bazı akarisitlere karşı tepkileri. Ankara Üniversitesi, Ziraat Fakültesi, Tarım Bilimleri Dergisi, 12 (3): $301-306$.

Ay, R. \& S. Yorulmaz, 2009. Bifenthrin'e dirençli Tetranychus urticae Koch (Acari:Tetranychidae)'de çoklu direnç, direnç kalıtımı ve sitokrom P450 aktivitesinin belirlenmesi. Bitki Koruma Bülteni, 49 (2): 67-78.

Blair, C.A. \& J.R. Groves, 1952. Biology of the fruittree red spider mite, Metatetranychus ulmi (Koch) Insouth-East England. Journal Horticultural Science, 27: 14-43.

Boyraz, N., S. Kaymak \& F. Yiğit, 2005. Eğirdir ilçesi elma üreticilerinin kimyasal savaşım uygulamalarının genel değerlendirilmesi. Selçuk Üniversitesi Ziraat Fakültesi Dergisi, 19(36):37-51.

Chant, D. C., 1966. Integrated control systems. scientific aspects of pest control. Washington D.C. Natural Academy Scientific Publications, 1402:193-218.

Croft, B. A., 1975. Integrated control of apple mites. Michigan state university extension service bulletin e-825, 12.

Demircan, V. \& H. Yılmaz, 2005. Isparta ili elma üretiminde tarımsal ilaç kullanımının çevresel duyarlılık ve ekonomik açıdan analizi. Ekoloji, 14(57): 15-25.

Hamingway, J., 1998. Techniques to detect insecticide resistance mechanisms (field and laboratory manual). World Health Organization Department Of Disease Prevention And Control, Who Communicable Diseases, 98:42. http://whqlibdoc.who.int/hq/1998/WHO_CDS_CPC_MAL_98.6.pdf?ua=1

Hu, J., C. Wang, J. Wang \& F. Chen , 2010. Monitoring of resistance to spirodiclofen and five other acaricides in Panonychus citri collected from Chinese citrus orchards. Pest Managment Science, 66: 1025-1030.

LeOra Software, 1994. POLO-PC:a User's Guide to Probit or Logit Analysis. LeOra Software, 28 p., Berkeley, CA.

Mobley, K.N. \& R. P. Marini, 1990. Gas exchange characteristics of apple and peach leaves infested by european red mite and twospotted spider mite. Journal American Society Horticultural Science, 115:757-761

Nauen, R., N. Stumpf, A. Elbert, C.P.W. Zebitz \& W. Kraus, 2001. Acaricide toxicity and resistance in larvae of different strains of Tetranychus urticae and Panonychus ulmi (Acari: Tetranychidae). Pest Management Science, 57: 253-261.

Sökeli, E., R. Ay \& İ. Karaca, 2007. Determination of the resistance level of two-spotted spider mite (Tetranychus urticae Koch) populations in apple orchards in Isparta province against some pesticides. Tarım Bilimleri Dergisi 13(4):326-330.

Tsagkarakou, A., T. V. Leeuwen, A. Khajehalit, M. Grispou, M. S. Williamsons, L. Tirry \& J. Vontas, 2009. Identification of pyrethroid resistance associated mutations in the para sodium channel of the Two Spotted Spider Mite Tetranychus urticae (Acari:Tetranychidae). Insect Molecular Biology, 18(5): 583-593.

Van Leeuwen, T. \& L. Tirry, 2007. Esterase-mediated bifenthrin resistance in a multiresistant strain of the two-spotted spider mite, Tetranychus urticae. Pest Management Science, 63:150-156. 